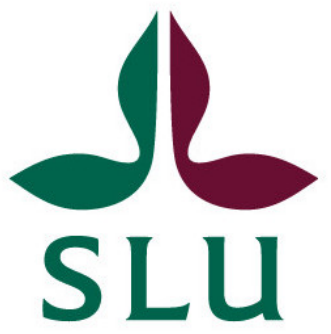

\title{
Influence of cropping and fertilization on soil pore characteristics in a long-term field study
}

David Nimblad Svensson

Master's Thesis in Soil Science $\boldsymbol{\bullet} 30$ credits

Swedish University of Agricultural Sciences, SLU

Faculty of Natural Resources and Agricultural Sciences

Soil, Water and Environment - Master's Programme

Examensarbeten, Institutionen för mark och miljö, SLU, 2020:04

Uppsala 2020 


\section{Influence of cropping and fertilization on soil pore characteristics in a long-term field study}

\section{David Nimblad Svensson}

Supervisor:

Assistant supervisor:

Assistant supervisor:

Assistant supervisor:

Examiner:

Credits:

Level:

Course title:

Course code:

Programme/education:

Course coordinating dept:

Place of publication:

Year of publication:

Cover picture:

Title of series:

Part number:

Keywords:
Johannes Koestel, SLU, Department of Soil and Environment Jumpei Fukumasu, SLU, Department of Soil and Environment Gunnar Börjesson, SLU, Department of Soil and Environment Tomas Kätterer, SLU, Department of Ecology Nicholas Jarvis, SLU, Department of Soil and Environment

30 credits

Second cycle, A2E

Master thesis in Soil science EX0880

Soil, Water and Environment - Master's Programme

Department of Soil and Environment

Uppsala

2020

Examensarbeten, Institutionen för mark och miljö, SLU 2020:04

X-ray CT, soil structure, biopores, connectivity

\section{Swedish University of Agricultural Sciences}

Faculty of Natural Resources and Agricultural Sciences

Department of Soil and Environment 


\section{Publishing and archiving}

Approved students' theses at SLU are published electronically. As a student, you have the copyright to your own work and need to approve the electronic publishing. If you check the box for YES, the full text (pdf file) and metadata will be visible and searchable online. If you check the box for NO, only the metadata and the abstract will be visiable and searchable online. Nevertheless, when the document is uploaded it will still be archived as a digital file.

If you are more than one author you all need to agree on a decision. You can find more information about publishing and archiving here: https://www.slu.se/en/ subweb/library/publish-and-analyse/register-and-publish/agreement-forpublishing/

YES, I/we hereby give permission to publish the present thesis in accordance with the SLU agreement regarding the transfer of the right to publish a work.

NO, I/we do not give permission to publish the present work. The work will still be archived and its metadata and abstract will be visible and searchable. 


\title{
Influence of cropping and fertilization on soil pore characteristics in a long-term field study
}

\author{
Abstract \\ Soil porosity, pore size distribution and pore characteristics such as connectivity are important for a \\ range of soil processes including ease of root growth and air and water transport. The pore structure is \\ therefore an important part of soil fertility. The pore space is sensitive to management practices such \\ as tillage, fertilization and cropping. Understanding how these practices influence the pore space is \\ important for maintaining a good soil structure that is well aerated and has sufficient drainage. X-ray \\ computed tomography has become a widely used method for studying the pore space as it offers the \\ advantage of enabling soil to be studied in its undisturbed form. In this study it was used to compare \\ the effects of crop growth, tillage and $\mathrm{N}$-fertilizing with $\mathrm{Ca}(\mathrm{NO} 3)_{2}$ or farm yard manure (FYM). Soil \\ samples were taken just below the surface from the long-term experiment in Ultuna, Sweden which \\ was started in 1956. The bare fallow, FYM and $\mathrm{Ca}(\mathrm{NO} 3)_{2}$-treatment were sampled with minimum \\ disturbance in two column sizes with inner diameters of 22.2 and $65.5 \mathrm{~mm}$. Differences in pore space \\ morphology were quantified and compared through pore size distribution and a range of connectivity \\ measures, including the Euler number, the critical pore diameter and Gamma connectivity. Biopores \\ were separated from non-biopores and their volume was quantified. Soil organic carbon was \\ determined by dry combustion. Visible porosity and pores in the $150-500 \mu \mathrm{m}$ class were significantly \\ larger in the FYM and $\mathrm{Ca}(\mathrm{NO} 3)_{2}$-treatment compared to the bare fallow. The porosity occupied by \\ biopores was not found to significantly differ between treatments but the biopores were found to have \\ the largest diameters in the FYM-treatment. Despite that the organic carbon content was 1.7 times \\ higher in the FYM compared to the $\mathrm{Ca}(\mathrm{NO} 3)_{2}$-treatment the visible porosity was similar. This may be \\ due to the positive effects that calcium has on the soil structure. The connectivity measures indicated \\ that the FYM-treatment had the best connected pore networks. This may be partly due to the larger \\ biopores. $\mathrm{Ca}(\mathrm{NO} 3)_{2}$ showed to be a promising alternative to increase porosity. However, as all the \\ management practices in the long-term field study are done by hand, future studies will have to \\ investigate if the effect is equally similar to FYM under field conditions which are subject to heavy \\ machineries.
}




\section{Popular science summary}

The development of advanced imaging techniques and analysis software has in many ways changed the way which soil physical quality is studied and understood. In the past, soil was mostly viewed from a solid phase perspective. With the advancement in image techniques such as X-ray tomography, soils could be studied in an undisturbed form and the pore perspective started to gain popularity.

The importance of the pore space lies in its influence on many soil processes, such as ease of root growth and plant available water as well as air, water and nutrient transport. The pore space consists of textural and structural pores. The textural pores are formed by the spatial distribution of the soil primary particles. The structural pores are formed by living organisms such as earthworms and growing roots but also from weather events such as freezing and drying. They are also created by tillage and are sensitive to compaction by both machineries and precipitation. Modern agriculture is often detrimental to soil structure and can cause problems such as erosion, runoff and decreased yield. To mitigate these problems, replacing inorganic fertilizer with some organic amendment has been suggested by some scientists.

This study focused on exploring how the pore size distribution, shape and connectedness of pores were affected by different treatments in a long-term study. The 'Ultuna long-term soil organic matter experiment' was started in 1956 in Uppsala, Sweden and consists of treatments that are amended with different sources of organic carbon and fertilizers. From this experiment the farmyard manure, the calcium nitrate and the bare fallow-treatments were chosen. Undisturbed soil samples were collected from these treatments and scanned with an industrial X-ray scanner. With the help of computer software, a range of measures were performed, including pore size distribution and separation of pores created by living organisms. The pore size distribution was found to be very similar in the calcium nitrate-treatment and the farmyard manure-treatment despite a large difference in carbon content, which is known to increase porosity. The reason for this is likely because the calcium in the calcium nitrate-treatment also had a positive effect on porosity. The results were indicative that the pore space in the farmyard manure-treatment had a better connectedness and this may have been due to its biopores which were larger than in the other treatments. 


\section{Table of contents}

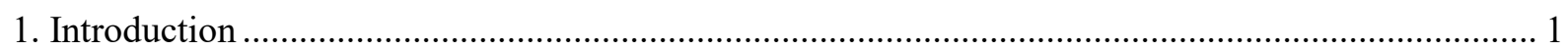

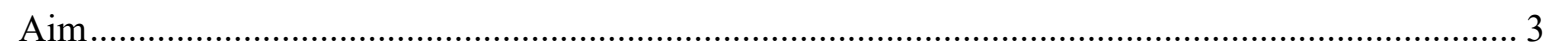

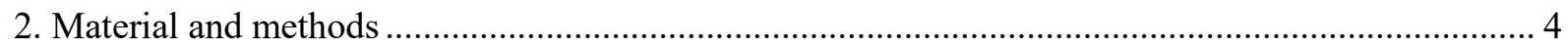

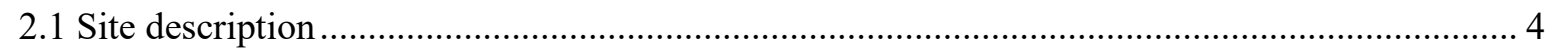

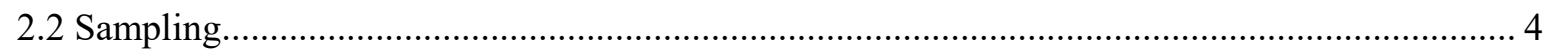

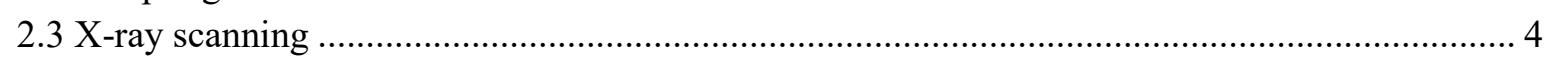

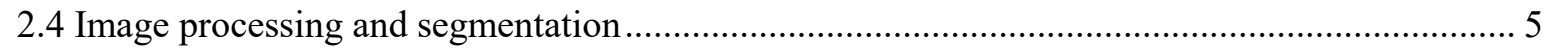

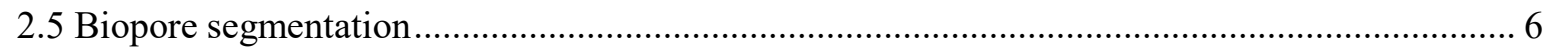

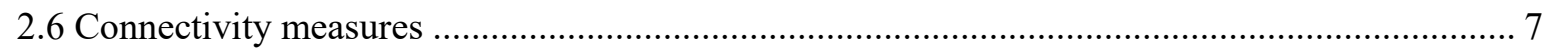

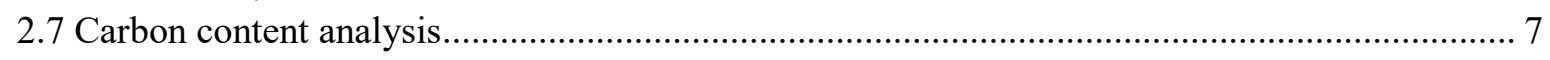

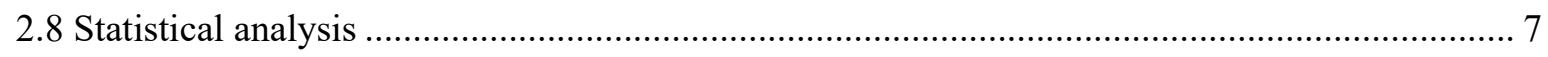

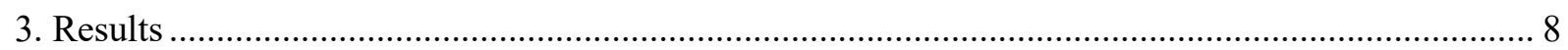

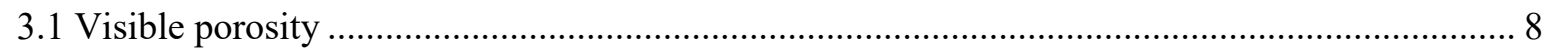

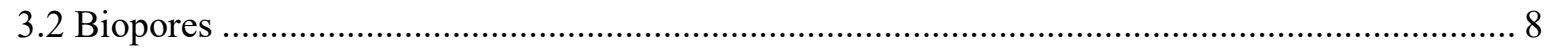

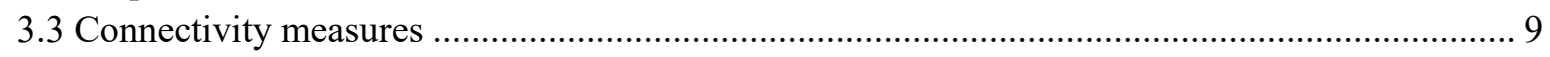

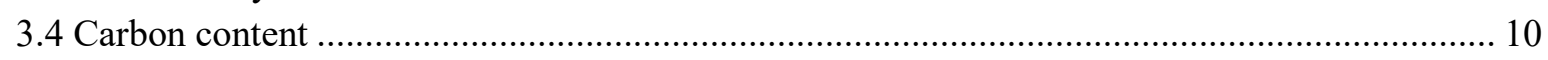

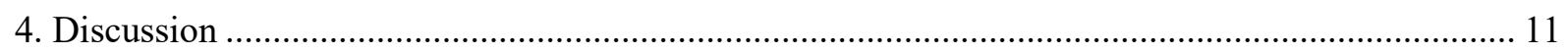

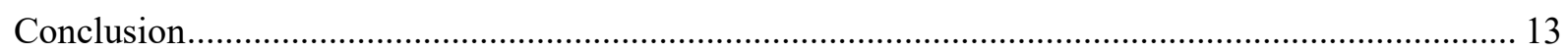

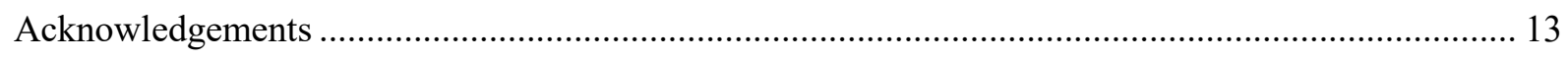

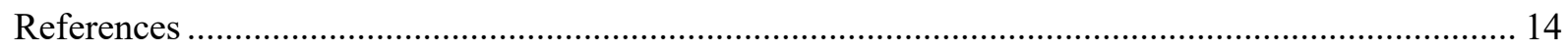

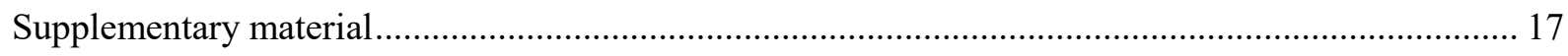




\section{Introduction}

It has been known for a long time that the size and shape of soil pores are important for the air and water transport as well as root penetration (Lawrence 1977). The pore system of the soil is also related to the water retention and the habitats for soil biota (Pires et al. 2017). Soil structure is referred to as "the spatial arrangement of solids and voids" by Rabot et al. (2018) and can be studied from either the solid phase or pore network perspective. The latter perspective is adopted here, as pores are best studied from direct methods rather than indirect measures.

To better understand the influence of pores, they may be described and distinguished in different ways. Structural pores are larger pores that are created from biotic and abiotic factors such as earthworms, climate and tillage. Textural pores on the other hand are typically smaller and are formed due to the spatial distribution of the soil primary particles. They are therefore less sensitive to management practices than the structural pores (Rabot et al. 2018). Pores may also be separated into biopores and non-biopores, which not only differ in their origin but also characteristics. Biopores are mainly created by root growth or burrowing soil fauna (Lal \& Shukla 2004) and are not very tortuous, cylindrical in shape, and often highly connected.

The air and water transport in soil is largely governed by the pore size distribution. In the case of water transport, Lal \& Shukla (2004) proposed that pores in the range of 0.5 to $50 \mu \mathrm{m}$ in equivalent cylindrical diameter can be considered storage pores that provide plants with water. They argued that pores smaller than $0.5 \mu \mathrm{m}$ retain water too strongly and pores larger than $50 \mu \mathrm{m}$ called transmission pores, are drained due to gravity. Other authors have suggested $0.2 \mu \mathrm{m}$ to be the lower boundary of plant available water (Abel et al. 2013). Transmission pores are also important for the air movement.

The connectivity of the pore network is important for a range of soil processes as well as for soil biota and plant growth (Rabot et al. 2018). It influences saturated hydraulic conductivity (Sandin et al. 2017), air permeability (Paradelo et al. 2016) and greenhouse gas emission by affecting the aeration status of the soil (Rabbi et al. 2016). Zhang et al. (2018) found that the connectivity for biopores was on average 8.13 times higher and that the mean pore volume was on average 55.1 times larger compared to non-biopores. Biopores can thus increase water infiltration, aeration and ease of root growth and provide pathways for roots to grow (Zhang et al. 2018; Lucas et al. 2019).

Many properties of the soil pore system are sensitive to land management. For example, as a consequence of the damage to soil structure caused by conventional tillage, the continuity of elongated transmission pores is decreased. This reduces water and solute transport, aeration and can lead to increasing runoff and soil erosion (Pagliai et al. 2004). Soil compaction can lead to reduced hydraulic conductivity, likely decreasing crop yield (Keller et al. 2012). Conventional farming practices with high mineral fertilizer has been found to be destructive to the pore structure ( $\mathrm{Lu}$ et al. 2019).

Soil organic carbon (SOC) has a large impact on the soil structure and soil processes including aggregation, water and nutrient retention and regulation of greenhouse gas emissions. It may also play an important role in preventing soil crust formation (Pagliai et al. 2004). An organic carbon content between 3-5\% was considered optimal by Reynolds et al. (2009) whereas Johannes et al. (2017) argued that clay content should be taken into account and proposed an organic carbon: Clay ratio of 1:8 as an optimum for soil quality. SOC also influences the porosity. For example, Naveed et al. 
(2014) found that total porosity increased linearly and macroporosity ( $>300 \mu \mathrm{m})$ exponentially with increasing carbon content. They attributed this to an increase in aggregation and a decrease in bulk density

Recommendations have been given to substitute some mineral fertilizer with manure to maintain SOC content and to increase macroaggregate formation (Ding et al. 2014; Zhao et al. 2019). Both manure and NPK-fertilizer increase root growth and thereby both the number of biopores and SOC from decaying roots and root exudates ( $\mathrm{Xu}$ et al. 2019). Moreover, manure is also a direct source of organic carbon and has been found to increase earthworm density (Edwards \& Lofty 1982). Recent studies have compared the impacts of mineral and organic fertilizers on the pore size distribution. Zhou et al. (2013) found a higher macroporosity (here $>500 \mu \mathrm{m}$ ) and a smaller mesoporosity $(<500 \mu \mathrm{m})$ in fields fertilized with both manure and mineral fertilizer compared to those not receiving manure. Pagliai $e t$ al. (2004) found pores $>500 \mu \mathrm{m}$ most abundant in soils treated with compost and a higher porosity in manure treated soils compared to the control. In a study by Dal Ferro et al. (2013) pores in the range of 560-1112 and 1112-2000 $\mu \mathrm{m}$ increased while pores in the range of 80-160 and 160-320 $\mu \mathrm{m}$ decreased with farmyard manure (FYM). Lu et al. (2019) and Yu et al. (2018) showed that pig manure increased the total porosity of pores $>80 \mu \mathrm{m}$ and $\mathrm{Lu}$ et al. (2019) also found $30-80 \mu \mathrm{m}$ pores to increase compared to NPK and control (no fertilizer) treatments. Lu et al. (2019) found nanoporosity to increase with NPK-fertilizer, leading to less plant available water.

In the context of comparing mineral to organic fertilizer, it seems that $\mathrm{Ca}(\mathrm{NO} 3)_{2}$ have not gained much attention even though $\mathrm{Ca}^{2+}$ is known to influence porosity. Divalent ions such as $\mathrm{Ca}^{2+}$ can act as a bridge between clay particles, aggregating them (Paradelo et al. 2013).

Mineral and organic fertilizers also seem to have different effects on the pore shape and connectivity. For example, Lu et al. (2019) found that pig manure treated soils had a higher proportion of pores that were irregular and elongated whereas the opposite was true in the NPK treated soil compared to the control. Yu et al. (2018) saw that the ratio of connected to isolated pores was lowest in NPKtreatment, higher in NPK + pig manure and highest in the pig manure only treatment. They also found that addition of straw increased the proportion of elongated pores and that pig manure increased connected porosity. Well-connected macropores (here $>80 \mu \mathrm{m}$ ), and with large importance for air, water and nutrient transport were found to be highly sensitive to different treatments. Dal Ferro et al. (2013) also found a higher connectivity in organically amended soils compared to mineral fertilized and unfertilized control.

The soil pore system may be improved by growing crops which have roots that are efficient at exploring the soil space. Lucas et al. (2019) studied biopores along an agricultural chronosequence and found that three years of Lucerne (Medicago sativa) followed by winter cereals for four years and finally regional, typical crop rotations, could effectively create a biopore space that reached its maximum volume in twelve years in the subsoil and six years in the top soil. Remarkably, only about $10 \%$ of the biopores in the topsoil were filled with roots. Even after tillage, fractions of biopores remained but with different characteristics (e.g. less elongated) than the intact biopores.

It was suggested by Lawrence (1977) that soil damage caused by modern agriculture could be evaluated from the change in pore size distribution. The measuring of pore size distribution was at the time predominantly made by means of volumetric methods, such as water desorption, nitrogen gas adsorption and mercury intrusion. These indirect measures rely on some function to obtain an 
equivalent diameter. The accuracy of these methods was questioned particularly for fine textured soils due to swelling and shrinking.

Development of imaging techniques and classifications of pores into different types was amongst others done by Ringrose-Voase \& Bullock (1984). They were using image analyzers to measure different types of pores from impregnated soil blocks in 2D. Today many pore studies rely on image techniques such as X-ray computed tomography together with image analysis. An advantage of such methods is that they are non-destructive and take into account the shape of the pores and is therefore useful for quantifying the connectivity (Rabot et al. 2018). Moreover, the porosity can also be quantified from the true shape of the pores. The range of the porosity that can be obtained depends on the resolution, which is usually related to the size of the sample (Wildenschild et al. 2002). However, the pore sizes that can be quantified by nitrogen gas adsorption and mercury intrusion remains much smaller and can be used as a complement to X-ray tomography ( $\mathrm{Lu}$ et al. 2019). A wide range of measurements that quantifies and describes the pore system can be used with image analysis, allowing for a detailed comparison between samples. Examples of these include the porosity, tortuosity, connectivity, and radius of pore throats (Rabot et al. 2018).

Several studies have already explored the effects of manure amendments and NPK-fertilizer on porosity and a range of pore characteristics. However, the results have been contradicting. For example, some studies have suggested that NPK-fertilizers have a decreasing effect on porosity and others an increasing. Because of these discrepancies there is still a need for more studies comparing their effects. In the present study, $\mathrm{Ca}(\mathrm{NO} 3)_{2}$ was used as $\mathrm{N}$-fertilizer, introducing $\mathrm{Ca}^{2+}$ as an additional component. Furthermore, few studies have included a bare fallow as control, which may be useful in order to separate the effects of crop growth from tillage.

\begin{abstract}
Aim
The aim of this study is to compare how manure amendment and $\mathrm{Ca}(\mathrm{NO} 3)_{2}$ affects the pore structure of the soil and evaluate their long term impact on soil physical quality. The effect of SOC and crop growth are also considered. The visible porosity in different size classes, the connectivity and the amount of biopores in each treatment is quantified and compared using X-ray computed microtomography. It was hypothesized that the FYM-treatment would have the greatest visible porosity and macroporosity $(>300 \mu \mathrm{m})$ and that the $\mathrm{Ca}(\mathrm{NO} 3)_{2}$-treatment would have a higher visible porosity than the bare fallow but lower than the FYM-treatment. Additionally, the FYM-treatment was expected to have the most connected pores and a higher proportion of biopores.
\end{abstract}




\section{Material and methods}

\subsection{Site description}

The 'Ultuna long-term soil organic matter experiment' is located in Uppsala, Sweden $\left(59.82^{\circ} \mathrm{N}\right.$, $17.65^{\circ} \mathrm{E}$ ) and has been ongoing since 1956 . The experiment is set up as a randomized block design and consists of 15 different treatments receiving various amendments, which has resulted in a large spread in SOC. Each treatment is replicated in four plots consisting of a $2 \times 2 \mathrm{~m}$ wide area delimited by steel frames. The management practices are all done by hand. All treatments (including the bare fallow) are tilled in the spring and receive a basic annual fertilizer of $20 \mathrm{~kg} \mathrm{P}$ and $35-38 \mathrm{~kg} \mathrm{~K}^{-1}$. The farmyard manure is applied biennially at rates of $9.5 \mathrm{tha}^{-1}$ of solid cow manure during odd years in the autumn, after harvest. The $\mathrm{Ca}\left(\mathrm{NO}_{3}\right)_{2}$ is applied at rates of $80 \mathrm{~kg} \mathrm{~N} \mathrm{ha}^{-1}$ annually. Since 2000 fodder maize has been grown (Kätterer et al. 2011).

\subsection{Sampling}

Sampling was done on the $3^{\text {rd }}$ of September 2019, before the harvest of the fodder maize. Two column sizes were used. The inner diameters of the columns were $22.2 \mathrm{~mm}$ and $65.5 \mathrm{~mm}$ and the height 25 $\mathrm{mm}$ and $74.8 \mathrm{~mm}$ respectively. Two samples from each plot were taken for both column sizes. This resulted in a total of four replicates per column size and treatment $(n=4)$, each replicate being the mean of the two measurements per plot. The samples were taken in between two rows of maize at a depth just below the surface. A drop hammer was used to insert the large columns into the soil, whereas a wooden post was used to push the small columns into the soil. The samples were stored in a cold room overnight. On the following day a test scan was performed for one of the small columns to see if the water content was low enough for the smallest pores to be air filled. As this was not the case, they were left in the drying room for ca 24 hours. The large columns were scanned without further drying due to time constraints.

\subsection{X-ray scanning}

The samples were imaged with a GE Phoenix X-ray scanner (v| tome $\mid \mathrm{x} 240)$. The scanner is equipped with a tungsten target and a GE 16" flat panel detector with 2024×2024 detector crystals. The small columns were scanned with a tube-voltage of $90 \mathrm{kV}$ and a current of $180 \mu \mathrm{A} .2000$ radiographs were obtained, where each radiograph was the average of three images with an exposure time of 200 milliseconds. A $0.4 \mathrm{~mm}$ thick copper filter was used to harden the beam. Binning was set to $1 \mathrm{x} 1$. The obtained pixel size was $15 \mu \mathrm{m}$ in each direction giving a resolution of approximately 30 $\mu \mathrm{m}$ (Figure 1). The larger columns were scanned with $180 \mathrm{kV}, 450 \mu \mathrm{A}$, and an exposure time of 131 milliseconds, without averaging and binning set to $2 \times 2$. A $0.8 \mathrm{~mm}$ thick copper filter was used. The obtained pixel size was $90 \mu \mathrm{m}$ and the resolution approximately $180 \mu \mathrm{m}$. The radiographs were used to reconstruct 3D images with GE image reconstruction software datos $\mid \mathrm{x}$. They were then exported to TIFF-files for further processing. 

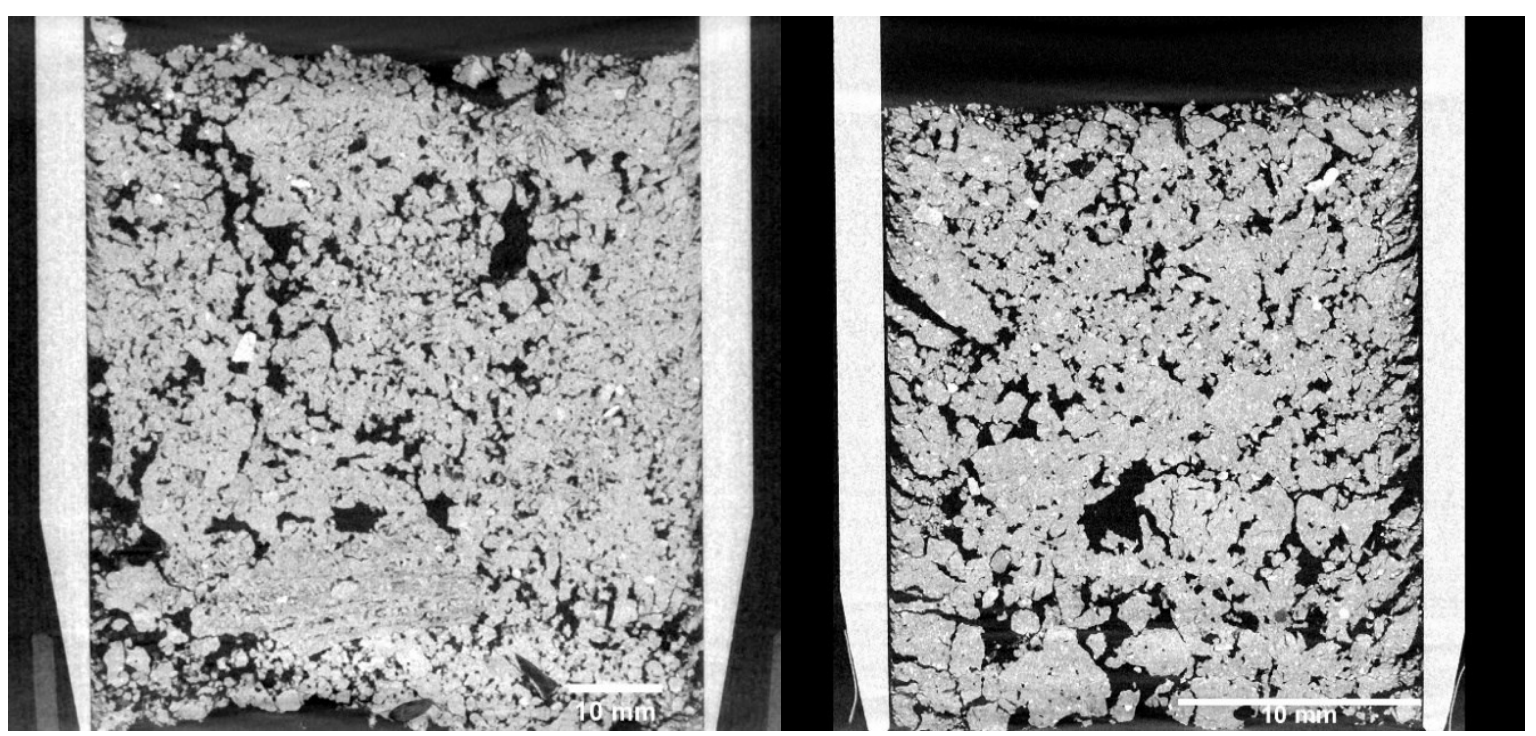

Figure 1. Differences in image quality and resolution obtained with the large (left) and small (right) column sizes.

\subsection{Image processing and segmentation}

All image processing was performed with the open-source software ImageJ/Fiji (Schindelin et al. 2012), including a range of free plugins. Firstly, the TIFF-files were exported to 3D stacks, straightened and centered using the plugin SoilJ (Koestel 2018). A 1x1x1 and a 2x2x2 median filter was applied to the large and small column image stacks, respectively. To aid the identification of the column wall coordinates with SoilJ, an unsharp mask (radius $=1$, mask $=0.60$ ) was applied. By using the air-filled pores and column walls (aluminum) as reference, the grey values were normalized to 500020000. Histograms for all image stacks were retrieved with SoilJ and used to determine a threshold value by the minimum method. In Matlab (MathWorks 2019), two joint histograms were created for all images of the large and small columns respectively (Figure 2). The lowest points on the joint histograms, between the two peaks representing air-filled pores and soil matrix were used for segmentation.
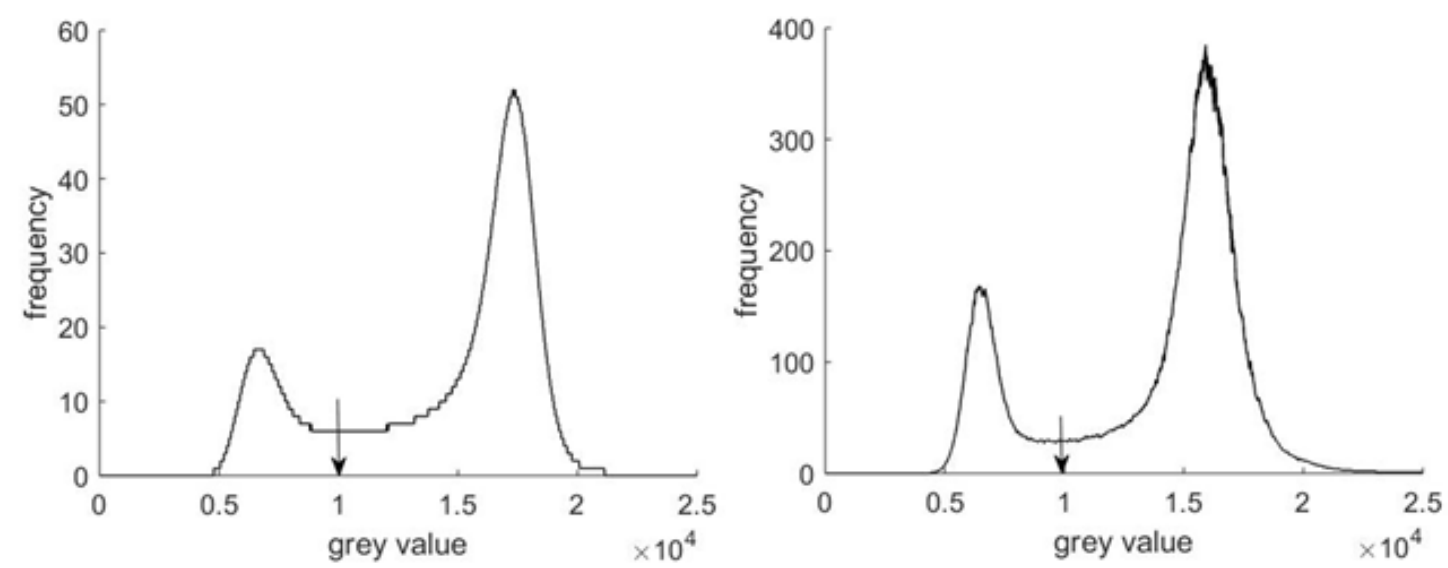

Figure 2. Joint histograms used to set the threshold value, indicated by the arrow for the large (left) and small (right) columns. 
For the small columns, a region of interest (ROI) that was $16.5 \mathrm{~mm}$ high and with a diameter of 19.2 $\mathrm{mm}$ was chosen. The ROI was localized in the center of the column, $3.75 \mathrm{~mm}$ below the top of the column. For the large columns, the selected ROI was $54 \mathrm{~mm}$ high and the diameter $47.7 \mathrm{~mm}$. It was also in the center of the column, $9 \mathrm{~mm}$ from the top of the column. Pore thickness maps were obtained with the "Pore Space Analyser" in SoilJ, which itself makes use of the plugin BoneJ (Doube et al. 2010) and MorphoLibJ (Legland et al. 2016). From them the pore size distribution was retrieved with the "extract pore size distribution" in SoilJ. The porosity was divided into pore size classes to reveal in which way different size classes are affected by the treatments.

\subsection{Biopore segmentation}

The biopore segmentation was only done on the large columns (Figure 3). All the biopores detected in this study were tubular in shape. The method was based on the approach published by Lucas et al. (2019), in which tubular features are distinguished from planar or blob-like features by scoring the eigenvalues of the Hesse matrix. Gaussian blur filters with standard deviations of up to 30 were applied to the binary images at different iterations to detect pores with different diameters. With larger standard deviations, pores with larger diameters are detected. A tubeness value of 60 was used as threshold. Since pores do not have smooth walls the detected pores were smaller than in the binary images from which they were segmented. Therefore, for each iteration, a number of 3D dilations were performed. The number of dilations were roughly half of the standard deviation. A filtering was applied which removed any pores that had a length to width ratio smaller than two.
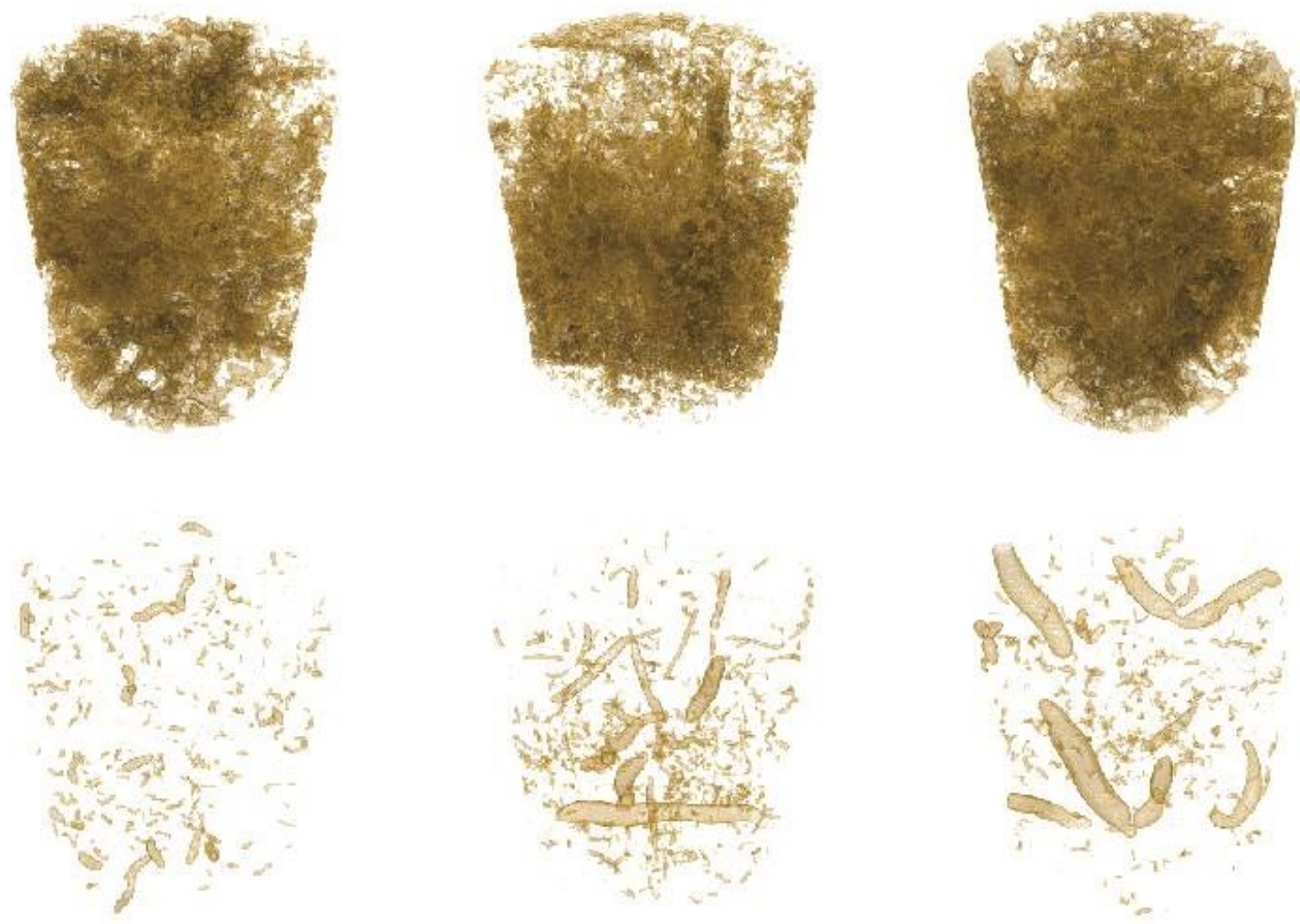

Figure 3. Examples of pore space before (top) and after biopore segmentation of the bare fallow, $\mathrm{Ca}(\mathrm{NO} 3)_{2}$ and FYMtreatment. 


\subsection{Connectivity measures}

The Euler number, Gamma, critical pore diameter and surface area connected to the top were used as measures of connectivity. The Euler number is the number of objects minus the number of redundant loops. Negative values therefore suggest a high connectivity and indicates that there are many connected pathways, which increases the aeration and water availability. Gamma is the likelihood that two randomly chosen pore voxels are connected and also gives an indication of the aeration and water availability. The critical pore diameter is the diameter of the largest sphere that could travel through from top to bottom of the imaged pore volume and is thus related to hydraulic conductivity. The surface area connected to the top was divided by the ROI volume and is a measure of aeration

\subsection{Carbon content analysis}

Total carbon and organic carbon were determined by dry combustion with the TruMac $\mathrm{CN}$-analyzer (LECO Corp.). Soil samples were taken from the small columns and were first crushed and sieved to 2 $\mathrm{mm}$.

\subsection{Statistical analysis}

For all statistical analysis, the average of the two replicates from each plot was used and the block effect was taken into account. A general linear model was used with the metric of interest as response and block and treatments as factors. The ANOVA assumptions of normality and homogeneity of the residuals were evaluated by residual plots. To overcome the non-normality of the Euler number it was first rank-transformed. All statistical analyses were carried out with the software Minitab version 18.1. $\mathrm{P}$-value $<0.05$ was adopted as a significant level and a $\mathrm{P}$-value $<0.1$ was seen as indicative results. 


\section{Results}

\subsection{Visible porosity}

An attempt to match the porosity curve obtained from the small and large columns resulted in a poor fit (Figure S1). Therefore, porosity was analyzed separately for the large and small columns. The large columns were used for the pores $>300 \mu \mathrm{m}$. In a cumulative distribution curve, it can be seen that the porosity mostly consists of pores $<500 \mu \mathrm{m}$ for the $\mathrm{FYM}$ and $\mathrm{Ca}\left(\mathrm{NO}_{3}\right)_{2}$-treatments (Figure $4 \mathrm{~A}$ ). The total porosity of these treatments did not statistically differ from each other but were significantly larger than the one for the bare fallow. The same significant difference was also found for the 150-500 $\mu \mathrm{m}$ pore class (Figure 4B).
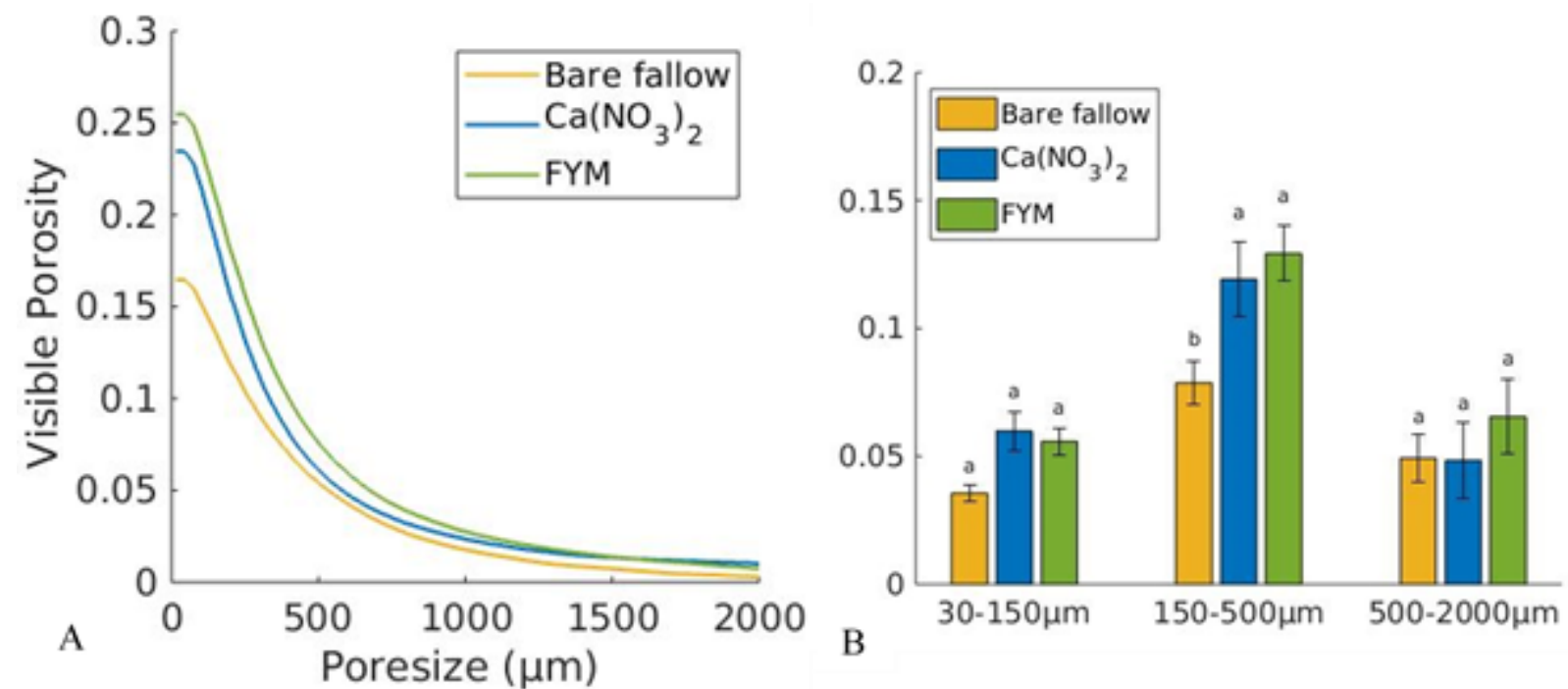

Figure 4. A: cumulative pore size distribution for pores $>30 \mu \mathrm{m}$ made using the small columns. Note that the curve is steepest for pores $<500 \mu \mathrm{m}$. B: porosity in three different size classes from the small columns. Bars that do not share a letter are significantly different (Tukey method).

Macroporosity $(>300 \mu \mathrm{m})$ obtained from the large columns was found to be higher in all treatments. For the large columns it was $0.12( \pm 0.01), 0.16( \pm 0.01)$ and $0.18( \pm 0.02)$ for the bare fallow, $\mathrm{Ca}\left(\mathrm{NO}_{3}\right)_{2}$ and FYM-treatments, respectively, whereas it was $0.09( \pm 0.00), 0.10( \pm 0.02)$ and $0.13( \pm 0.02)$ for the small columns. The differences in macroporosity obtained from the large columns was significant at $90 \%$ confidence. A grouping based on the Tukey method grouped FYM as significantly higher compared to the bare fallow but not $\mathrm{Ca}\left(\mathrm{NO}_{3}\right)_{2}$.

\subsection{Biopores}

The porosity occupied by biopores (hereafter referred to as bioporosity) was not significantly different between the treatments. A notable difference was seen in the distribution of biopores, where the FYM contained biopores with larger diameters than the other treatments (figure 5). 


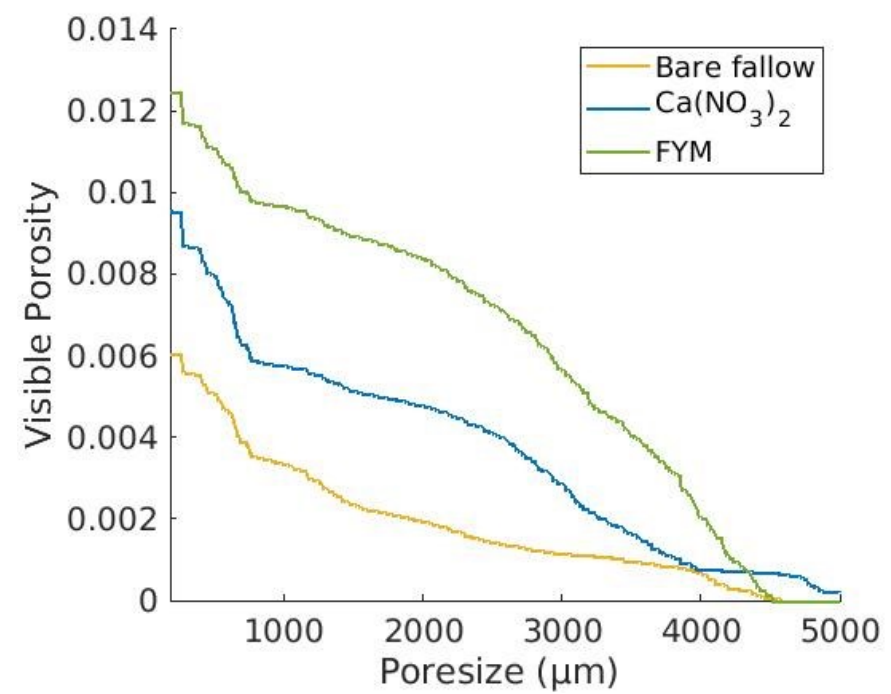

Figure 5. Cumulative pore size distribution of biopores larger than $180 \mu \mathrm{m}$ from the large columns.

\subsection{Connectivity measures}

The Gamma value was significantly higher in FYM and $\mathrm{Ca}\left(\mathrm{NO}_{3}\right)_{2}$ compared to the bare fallow in the small columns (Table 1). In the large columns, Gamma was significantly higher in FYM compared to the bare fallow at $\mathrm{p}<0.1$. The mean critical pore diameter was largest in the FYM in both the small and large columns. The Euler number was significantly smaller in the FYM-treatment compared to the bare fallow. The surface area connected to the top was significantly higher in the $\mathrm{Ca}\left(\mathrm{NO}_{3}\right)_{2}$ and FYMtreatment compared to the bare fallow.

Table 1. Connectivity measures for the small columns. Different letters indicate significant differences $(\mathrm{P}<0.05)$ between treatments, * indicate $\mathrm{P}<0.1$.

\begin{tabular}{llll} 
Small columns & Bare fallow & $\mathrm{Ca}\left(\mathrm{NO}_{3}\right)_{2}$ & $\mathrm{FYM}$ \\
\hline Euler & $29707 \pm 2677 \mathrm{a}$ & $2111 \pm 7317 \mathrm{ab}$ & $643 \pm 4022 \mathrm{~b}$ \\
Gamma & $0,88 \pm 0,02 \mathrm{~b}$ & $0,96 \pm 0,01 \mathrm{a}$ & $0,96 \pm 0,01 \mathrm{a}$ \\
Critical pore diameter $(\mu \mathrm{m})$ & $205 \pm 12$ & $221 \pm 50$ & $267 \pm 32$ \\
Surface area connected to top $\left(\mathrm{cm}^{2}\right)$ & $96 \pm 13$ & $151 \pm 22$ & $114 \pm 29$ \\
Large columns & & & \\
\hline Euler & $5228 \pm 1994$ & $6788 \pm 2627$ & $202 \pm 3890$ \\
Gamma & $0,77 \pm 0,07 \mathrm{~b}^{*}$ & $0,90 \pm 0,02 \mathrm{ab}^{*}$ & $0,93 \pm 0,02 \mathrm{a}^{*}$ \\
Critical pore diameter $(\mu \mathrm{m})$ & $707 \pm 130$ & $534 \pm 56$ & $820 \pm 168$ \\
Surface area connected to top $\left(\mathrm{cm}^{2}\right)$ & $429 \pm 55 \mathrm{~b}$ & $729 \pm 56 \mathrm{a}$ & $724 \pm 85 \mathrm{a}$ \\
\hline
\end{tabular}




\subsection{Carbon content}

The highest SOC content was, as expected found in the FYM-treatment. The SOC content was on average 1.7 and 2.4 times higher in the FYM-treatment compared to the $\mathrm{Ca}\left(\mathrm{NO}_{3}\right)_{2}$ and the bare fallowtreatments respectively. This increase in SOC content was accompanied with an increase in total porosity when comparing the FYM to the bare fallow, but not compared to the $\mathrm{Ca}\left(\mathrm{NO}_{3}\right)_{2}$ (Figure 6).

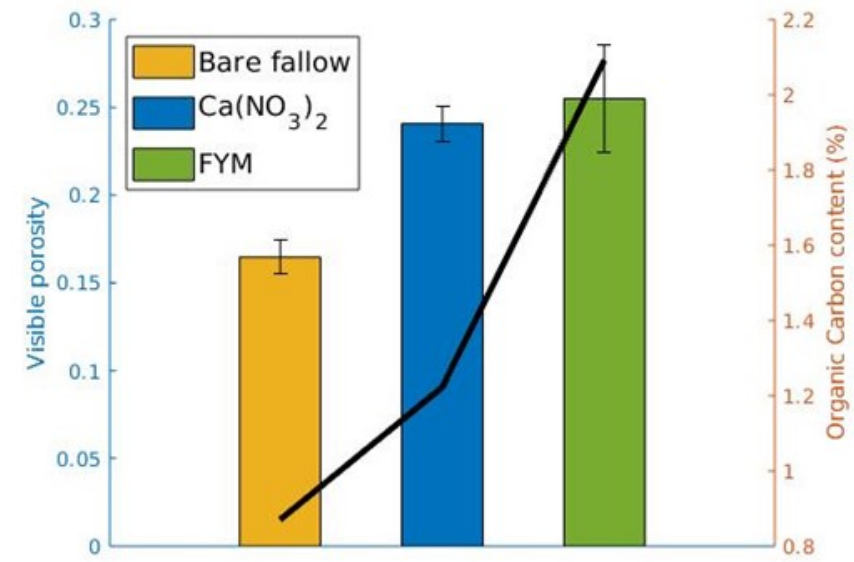

Figure 6. Visible porosity and SOC obtained from the small columns. Bars show visible porosity and the line shows the SOC. Despite the higher SOC content in the FYM, the porosity is not significantly higher than in the $\mathrm{Ca}\left(\mathrm{NO}_{3}\right)_{2}$-treatment. 


\section{Discussion}

Combining the porosity curve from the small and large columns was considered a good strategy to obtain a more representable result. The cause of the poor fit may have been that the pores were insufficiently drained in the large columns. It could also have been due to the relatively lower image resolution. For these reasons, the large columns were only used for pores $>300 \mu \mathrm{m}$. A possibility could have been to include a third sample with a diameter in between the sizes used in this study, or to take subsamples from a column with each subsequent sample having a smaller diameter than the previous one. Such a hierarchical sampling strategy was successfully implemented by Lucas et al. (2019).

The total porosity did not significantly differ between the FYM and $\mathrm{Ca}\left(\mathrm{NO}_{3}\right)_{2}$-treatments despite the larger SOC content in the FYM-treatment. A plausible explanation for this is that the $\mathrm{Ca}^{2+}$ might compensate this deficit. A number of studies supports this theory. For example, Marchuk et al. (2012) used X-ray tomography to compare impacts of some mono- and divalent cations on the visible porosity and were able to show that $\mathrm{Ca}^{2+}$ increases it and that $\mathrm{K}^{+}$decreases it. Similarly, Ferreira et al . (2018) found that liming with $\mathrm{CaO}$ and $\mathrm{MgO}$ increased soil porosity and the amount of elongated and well connected pores. Grieve et al. (2005) also found a higher porosity in limed soil compared to nonlimed. The findings in this study supports the hypothesis that organic amendments should improve the soil porosity through improved aggregate stability, but not that all mineral fertilizers deteriorate soil structure. Instead $\mathrm{Ca}\left(\mathrm{NO}_{3}\right)_{2}$ appears to be a viable option as $\mathrm{N}$-fertilizer with regards to the pore structure.

Despite the emerging evidence that manure and NPK have contrasting effects on the pore size distribution, some other studies were also not able to detect such a difference. In Schjønning et al. (2005) it was proposed that a greater macroporosity was achieved regardless of the origin of the nutrient source (mineral or organic) due to the improved root growth. Naveed et al. (2014) found an increase in macroporosity with manure alone and an even greater increase and with manure + NPK. Furthermore, different studies have found manure to have contradicting effects on the pore size distribution. Three plausible explanations are that (i) the soil texture not being favorable, perhaps due to a high sand content (ii) too little amendment was added (iii) the manure that was used had not been well composted. Non-composted manure may contain high levels of $\mathrm{NH}_{4}^{+}$(Eghball et al. 2002) or $\mathrm{K}^{+}$ (Haynes \& Naidu 1998), which could act as dispersing agents. In this study, all treatments received the same amount of mineral $\mathrm{K}^{+}$, but the FYM likely already contained some. Thus, it cannot be ruled out that the pore structure of the FYM-treatment was not affected by this larger concentration. Moreover, manure that is composted is less decomposable and leads to less $\mathrm{C}$ loss when it is applied compared to manure slurry (Mori \& Hojito 2015). Unfortunately, the quality of the manure seems to have been an overlooked factor. Recent studies have highlighted another issue with manure; it often contains high levels of $\mathrm{Na}+$ which can be detrimental to soil structure by acting as a dispersant (Guo et al. 2019).

In this study, the time of the FYM application may have affected its influence on porosity. The FYM was applied almost two years prior to sampling, which may have had an influence on the result. For example, Loveland (2003) suggested that fresh organic matter may be more important for aggregation. However, Bhogal et al. (2011) compared the effects of recent (6 months) and historic (at least 2 years old) additions of manure in a long term experiment and found no significant differences in porosity obtained from bulk density and particle density.

Crop growth was expected to result in a larger porosity due to an increase in SOC and bioporosity. Since the sampling was done between the crops, only a small number of roots were included in the 
columns. However, old root channels from previous seasons should still have existed even if only as fractions. Indeed, a visual inspection suggested that some biopores were elongated but cut, likely due to tillage. Thus, it was surprising that the differences in bioporosities were non-significant. A notable difference was seen in the size distribution of the biopores larger than $180 \mu \mathrm{m}$, where the FYMtreatment on average contained pores of larger diameters. The reason for this is possibly due to an increase in soil faunal activity.

All of the connectivity measurements indicated that the FYM-treatment was better connected than the $\mathrm{Ca}\left(\mathrm{NO}_{3}\right)_{2}$-treatment, even though the differences were not significant. The $\mathrm{Ca}\left(\mathrm{NO}_{3}\right)_{2}$-treatment was in turn better connected than the bare fallow. These indications suggests that addition of FYM increases the pore connections to a greater extent than $\mathrm{Ca}\left(\mathrm{NO}_{3}\right)_{2}$. Lu et al. (2019) also found an increase in connectivity with pig manure. The reason for this finding is suggested to at least partly be due to the larger diameter in the biopores in the FYM-treatment.

For soils that have soil physical qualities far from optimum, vast amounts of organic amendments might be required to shift the physical properties into their optimum range. Reynolds et al. (2009) compared the effects of 75 and $300 \mathrm{t} \mathrm{ha}^{-1}$ (dry weight) of compost on a range of parameters.

Application of $75 \mathrm{t} \mathrm{ha}^{-1}$ improved most of the parameters and improved air capacity, macroporosity, SOC and stability index to their optimum range. With the application of $300 \mathrm{t} \mathrm{ha}^{-1}$, the relative field capacity, plant-available water capacity, bulk density were also improved to their optimum range. Reynolds et al. (2009) recommended a macroporosity $(>300 \mu \mathrm{m})$ above $0.07 \mathrm{~m}^{3} \mathrm{~m}^{-3}$ and a critical lower limit to be $0.04 \mathrm{~m}^{3} \mathrm{~m}^{-3}$. In the control in that study, the porosity was 0.06 and increased to 0.08 and 0.11 with the low and high compost rates respectively. In the present study, no values below the recommendation were found, indicating that macroporosity was sufficiently high in all treatments. This is likely because the field site is managed by hand, thus avoiding compaction by heavy machinery.

To some extent, the measurements conducted in the present and similar studies, characterize the soils ability to withstand the compacting effects of precipitation following tillage. Precipitation leads to a reduction in porosity that is disproportionally higher for macropores (Sandin et al. 2017; Kool et al. 2019). The degree of the effect is also dependent on the soil texture and aggregation (van Es et al. 1999). In the present study, the macroporosity $(>300 \mu \mathrm{m})$ was slightly larger in the FYM-treatment, indicating a better ability to withstand the compaction of precipitation. Similarly to this observation, Schlüter et al. (2011) saw an increase in resilience to compaction after tillage in a plot fertilized with manure and NPK-fertilizer in a long term experiment.

The methodology in this study proved suitable for exploring the effects of fertilization with $\mathrm{Ca}\left(\mathrm{NO}_{3}\right)_{2}$ and FYM. It was however not possible to quantify the overall increase in porosity due to crop growth due to the simultaneous effects of FYM and $\mathrm{Ca}^{2+}$ on the soil structure. This would have been possible if an unfertilized treatment had been included and compared to the bare fallow. Furthermore, the variation was quite high for most of the metrics and therefore it would have been helpful to include more replicates. The biopore script gave results in the same range as those obtained by Lucas et al. (2019). It worked reasonably well and was useful for comparing the treatments. However, there is still room for improvement. The filtering which was used, sometimes removed what appeared to be biopores. On the other hand, not including the filter resulted in a considerable increase in pores and based on their appearance most of those did not seem to be biopores. It appears fruitful to further develop the biopore detection approach for future studies. 


\section{Conclusion}

The farm yard manure and $\mathrm{Ca}\left(\mathrm{NO}_{3}\right)_{2}$-treatments had a higher visible porosity obtained from the small columns compared to the bare fallow. The porosity of the $\mathrm{Ca}\left(\mathrm{NO}_{3}\right)_{2}$-treatment was not significantly different from the farmyard manure despite its lower carbon content. The calcium is thought to compensate for this deficit and $\mathrm{Ca}\left(\mathrm{NO}_{3}\right)_{2}$ may therefore be an option to improve soil structure without adding organic amendments.

The extent to which crop growth increased porosity in the different treatments was not possible to quantify in this experimental setup. An unfertilized treatment with crop would have been useful for this purpose. The difference in porosity obtained from the small columns was most pronounced in the $150-500 \mu \mathrm{m}$ class, which was significantly larger for the farm yard manure and $\mathrm{Ca}\left(\mathrm{NO}_{3}\right)_{2}$-treatment compared to the bare fallow. The results were indicative $(\mathrm{p}<0.1)$ that macroporosity $(>300 \mu \mathrm{m})$ obtained from the large columns was larger in the farmyard manure compared to the bare fallow. The connectivity measures indicated that the farm yard manure-treatment increased the connectivity more than the $\mathrm{Ca}\left(\mathrm{NO}_{3}\right)_{2}$-treatment. The reason for this may partly be due to the biopores in the farmyard manure, which were larger in diameter than in the other treatments.

Further work is needed to test if $\mathrm{Ca}\left(\mathrm{NO}_{3}\right)_{2}$ and farmyard manure would give the same results if applied to fields that are subject to heavy machineries. How the porosities changes over the growing seasons and the importance of the quality of the organic amendment should also be investigated.

\section{Acknowledgements}

Many thanks to my main supervisor John Koestel for all your support throughout the project. Thanks to my Co-supervisors Jumpei Fukumasu, for many great conversations and help with writing and to Gunnar Börjesson for help with writing and guidance at the 'Ultuna long-term soil organic matter experiment'. Finally, I would also like to thank Mats Larsbo who built the biopore script which was adopted for this thesis. 


\section{References}

Abel, S., Peters, A., Trinks, S., Schonsky, H., Facklam, M. \& Wessolek, G. (2013). Impact of biochar and hydrochar addition on water retention and water repellency of sandy soil. Geoderma, vol. 202-203, pp. 183-191

Bhogal, A., Nicholson, F.A., Young, I., Sturrock, C., Whitmore, A.P. \& Chambers, B.J. (2011). Effects of recent and accumulated livestock manure carbon additions on soil fertility and quality. European Journal of Soil Science, vol. 62 (1), pp. 174-181

Dal Ferro, N., Charrier, P. \& Morari, F. (2013). Dual-scale micro-CT assessment of soil structure in a long-term fertilization experiment. Geoderma, vol. 204-205, pp. 84-93

Ding, X., Yuan, Y., Liang, Y., Li, L. \& Han, X. (2014). Impact of long-term application of manure, crop residue, and mineral fertilizer on organic carbon pools and crop yields in a Mollisol. Journal of Soils and Sediments, vol. 14 (5), pp. 854-859

Doube, M., Kłosowski, M.M., Arganda-Carreras, I., Cordelières, F.P., Dougherty, R.P., Jackson, J.S., Schmid, B., Hutchinson, J.R. \& Shefelbine, S.J. (2010). BoneJ: Free and extensible bone image analysis in ImageJ. Bone, vol. 47 (6), pp. 1076-1079

Edwards, C.A. \& Lofty, J.R. (1982). Nitrogenous fertilizers and earthworm populations in agricultural soils. Soil Biology and Biochemistry, vol. 14 (5), pp. 515-521

Eghball, B., Wienhold, B.J., Gilley, J.E. \& Eigenberg, R.A. (2002). Mineralization of manure nutrients. Journal of Soil and Water Conservation, vol. 57 (6), pp. 470-473

van Es, H.M., Ogden, C.B., Hill, R.L., Schindelbeck, R.R. \& Tsegaye, T. (1999). Integrated Assessment of Space, Time, and Management-Related Variability of Soil Hydraulic Properties. Soil Science Society of America Journal, vol. 63 (6), p. 1599-1608

Ferreira, T.R., Pires, L.F., Wildenschild, D., Heck, R.J. \& Antonino, A.C.D. (2018). X-ray microtomography analysis of lime application effects on soil porous system. Geoderma, vol. 324, pp. 119-130

Grieve, I.C., Davidson, D.A. \& Bruneau, P.M.C. (2005). Effects of liming on void space and aggregation in an upland grassland soil. Geoderma, vol. 125 (1-2), pp. 39-48

Guo, Z., Zhang, J., Fan, J., Yang, X., Yi, Y., Han, X., Wang, D., Zhu, P. \& Peng, X. (2019). Does animal manure application improve soil aggregation? Insights from nine long-term fertilization experiments. Science of The Total Environment, vol. 660, pp. 1029-1037

Haynes, R.J. \& Naidu, R. (1998). Influence of lime, fertilizer and manure applications on soil organic matter content and soil physical conditions: a review. Nutrient Cycling in Agroecosystems, vol. 51 (2), pp. 123-137

Johannes, A., Matter, A., Schulin, R., Weisskopf, P., Baveye, P.C. \& Boivin, P. (2017). Optimal organic carbon values for soil structure quality of arable soils. Does clay content matter? Geoderma, vol. 302, pp. 14-21

Keller, T., Sutter, J.A., Nissen, K. \& Rydberg, T. (2012). Using field measurement of saturated soil hydraulic conductivity to detect low-yielding zones in three Swedish fields. Soil and Tillage Research, vol. 124, pp. 68-77

Koestel, J. (2018). SoilJ: an ImageJ plugin for the semiautomatic processing of three-dimensional Xray images of soils. Vadose Zone Journal, vol. 17 (1), pp. 1-7

Kool, D., Tong, B., Tian, Z., Heitman, J.L., Sauer, T.J. \& Horton, R. (2019). Soil water retention and hydraulic conductivity dynamics following tillage. Soil and Tillage Research, vol. 193, pp. $95-100$

Kätterer, T., Bolinder, M.A., Andrén, O., Kirchmann, H. \& Menichetti, L. (2011). Roots contribute more to refractory soil organic matter than above-ground crop residues, as revealed by a longterm field experiment. Agriculture, Ecosystems \& Environment, vol. 141 (1-2), pp. 184-192 
Lal, R. \& Shukla, M.K. (2004). Principles of soil physics. CRC Press.

Lawrence, G.P. (1977). Measurement of pore sizes in fine-textured soils: A review of existing techniques. Journal of Soil Science, vol. 28 (4), pp. 527-540

Legland, D., Arganda-Carreras, I. \& Andrey, P. (2016). MorphoLibJ: integrated library and plugins for mathematical morphology with ImageJ. Bioinformatics, p. btw413

Loveland, P. (2003). Is there a critical level of organic matter in the agricultural soils of temperate regions: a review. Soil and Tillage Research, vol. 70 (1), pp. 1-18

Lu, S., Yu, X. \& Zong, Y. (2019). Nano-microscale porosity and pore size distribution in aggregates of paddy soil as affected by long-term mineral and organic fertilization under rice-wheat cropping system. Soil and Tillage Research, vol. 186, pp. 191-199

Lucas, M., Schlüter, S., Vogel, H.-J. \& Vetterlein, D. (2019). Soil structure formation along an agricultural chronosequence. Geoderma, vol. 350, pp. 61-72

Marchuk, A., Rengasamy, P., McNeill, A. \& Kumar, A. (2012). Nature of the clay - cation bond affects soil structure as verified by X-ray computed tomography. Soil Research, vol. 50 (8), p. 638-644

MathWorks, M. (2019). The Mathworks. Inc., Natick, MA,

Mori, A. \& Hojito, M. (2015). Effect of dairy manure type on the carbon balance of mowed grassland in Nasu, Japan: comparison between manure slurry plus synthetic fertilizer plots and farmyard manure plus synthetic fertilizer plots. Soil Science and Plant Nutrition, vol. 61 (4), pp. 736746

Naveed, M., Moldrup, P., Vogel, H.-Jö., Lamandé, M., Wildenschild, D., Tuller, M. \& de Jonge, L.W. (2014). Impact of long-term fertilization practice on soil structure evolution. Geoderma, vol. 217-218, pp. 181-189

Pagliai, M., Vignozzi, N. \& Pellegrini, S. (2004). Soil structure and the effect of management practices. Soil and Tillage Research, vol. 79 (2), pp. 131-143

Paradelo, M., Katuwal, S., Moldrup, P., Norgaard, T., Herath, L. \& de Jonge, L.W. (2016). X-ray CTDerived Soil Characteristics Explain Varying Air, Water, and Solute Transport Properties across a Loamy Field. Vadose Zone Journal, vol. 15 (4), pp.1-13

Paradelo, R., van Oort, F. \& Chenu, C. (2013). Water-dispersible clay in bare fallow soils after 80years of continuous fertilizer addition. Geoderma, vol. 200-201, pp. 40-44

Pires, L.F., Borges, J.A.R., Rosa, J.A., Cooper, M., Heck, R.J., Passoni, S. \& Roque, W.L. (2017). Soil structure changes induced by tillage systems. Soil and Tillage Research, vol. 165, pp. 66-79

Rabbi, S.M.F., Daniel, H., Lockwood, P.V., Macdonald, C., Pereg, L., Tighe, M., Wilson, B.R. \& Young, I.M. (2016). Physical soil architectural traits are functionally linked to carbon decomposition and bacterial diversity. Scientific Reports, vol. 6 (1), p. 33012

Rabot, E., Wiesmeier, M., Schlüter, S. \& Vogel, H.-J. (2018). Soil structure as an indicator of soil functions: A review. Geoderma, vol. 314, pp. 122-137

Reynolds, W.D., Drury, C.F., Tan, C.S., Fox, C.A. \& Yang, X.M. (2009). Use of indicators and pore volume-function characteristics to quantify soil physical quality. Geoderma, vol. 152 (3-4), pp. 252-263

Ringrose-Voase, A.J. \& Bullock, P. (1984). The automatic recognition and measurement of soil pore types by image analysis and computer programs. Journal of Soil Science, vol. 35 (4), pp. 673684

Sandin, M., Koestel, J., Jarvis, N. \& Larsbo, M. (2017). Post-tillage evolution of structural pore space and saturated and near-saturated hydraulic conductivity in a clay loam soil. Soil and Tillage Research, vol. 165, pp. 161-168

Schindelin, J., Arganda-Carreras, I., Frise, E., Kaynig, V., Longair, M., Pietzsch, T., Preibisch, S., Rueden, C., Saalfeld, S., Schmid, B., Tinevez, J.-Y., White, D.J., Hartenstein, V., Eliceiri, K., 
Tomancak, P. \& Cardona, A. (2012). Fiji: an open-source platform for biological-image analysis. Nature Methods, vol. 9 (7), pp. 676-682

Schjønning, P., Iversen, B.V., Munkholm, L.J., Labouriau, R. \& Jacobsen, O.H. (2005). Pore characteristics and hydraulic properties of a sandy loam supplied for a century with either animal manure or mineral fertilizers. Soil Use and Management, vol. 21 (3), pp. 265-275

Schlüter, S., Weller, U. \& Vogel, H.-J. (2011). Soil-structure development including seasonal dynamics in a long-term fertilization experiment. Journal of Plant Nutrition and Soil Science, vol. 174 (3), pp. 395-403

Wildenschild, D., Vaz, C.M.P., Rivers, M.L., Rikard, D. \& Christensen, B.S.B. (2002). Using X-ray computed tomography in hydrology: systems, resolutions, and limitations. Journal of Hydrology, vol. 267 (3-4), pp. 285-297

Xu, H., Vandecasteele, B., Zavattaro, L., Sacco, D., Wendland, M., Boeckx, P., Haesaert, G. \& Sleutel, S. (2019). Maize root-derived C in soil and the role of physical protection on its relative stability over shoot-derived C. European Journal of Soil Science, vol. 70(5), pp. 935946

Yu, X., Hong, C., Peng, G. \& Lu, S. (2018). Response of pore structures to long-term fertilization by a combination of synchrotron radiation X-ray microcomputed tomography and a pore network model: Effect of long-term fertilization on soil pore structure. European Journal of Soil Science, vol. 69 (2), pp. 290-302

Zhang, Z., Liu, K., Zhou, H., Lin, H., Li, D. \& Peng, X. (2018). Three dimensional characteristics of biopores and non-biopores in the subsoil respond differently to land use and fertilization. Plant and Soil, vol. 428 (1-2), pp. 453-467

Zhao, Z., Zhang, C., Zhang, J., Liu, C. \& Wu, Q. (2019). Effects of Substituting Manure for Fertilizer on Aggregation and Aggregate Associated Carbon and Nitrogen in a Vertisol. Agronomy Journal, vol. 111 (1), pp. 368-377

Zhou, H., Peng, X., Perfect, E., Xiao, T. \& Peng, G. (2013). Effects of organic and inorganic fertilization on soil aggregation in an Ultisol as characterized by synchrotron based X-ray micro-computed tomography. Geoderma, vol. 195-196, pp. 23-30 


\section{Supplementary material}

Plot of the fit between large and small columns.

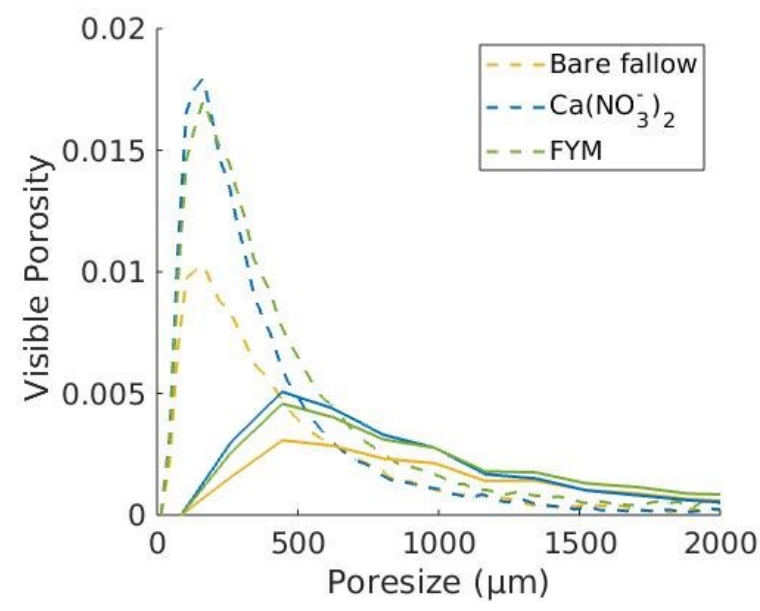

Figure S1. Combined pore size distribution. The dotted line was obtained from the small columns and the solid line from the large. 